\title{
Stigma terhadap Orang dengan HIV dan AIDS (ODHA) pada Masyarakat di Kelurahan Kayu Merah Kota Ternate Tahun 2019
}

\author{
Emamalina Asra1 $^{1}$, Nani Supriyatni ${ }^{\circledR}$, Suryani Mansyur ${ }^{3}$ \\ ${ }^{1}$ Mahasiswa Peminatan Epidemiologi Fakultas Ilmu Kesehatan, Universitas Muhammadiyah Maluku Utara. Ternate. \\ Indonesia, \\ Email : emamalina98@gmail.com \\ 2 Staf PengajarFakultas Ilmu Kesehatan, Universitas Muhammadiyah Maluku Utara. Ternate. Indonesia, \\ Email : naniskm@yahoo.com \\ 3 Staf PengajarFakultas Ilmu Kesehatan, Universitas Muhammadiyah Maluku Utara. Ternate. Indonesia, \\ Email : ryanimansyur@gmail.com

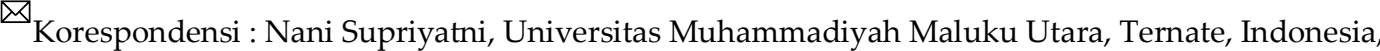 \\ Email :naniskm@yahoo.com
}

\begin{abstract}
ABSTRAK.
Stigma adalah suatu sifat yang menghubungkan seseorang yang terinfeksi HIV dengan nilainilai negatif yang diberikan oleh masyarakat. Pemberian Stigma membuat ODHA diperlakukan secara berbeda dengan orang lain dan dapat menghambat proses pengobatan dan dapat meningkatkan jumlah pengidap AIDS. Jenis penelitian ini adalah penelitian Survey Analitik dengan rancangan Cross Sectional Study.Pengumpulan data menggunakan koesener untuk megidentifikasi variabel penelitian.Pengelolaan data menggunakan komputerisasi dengan menggunakan program spss dan analisis data menggunakan analisis Chi-square.Penyajian data penelitian dalam bentuk tabel dari populasi pada penelitian ini adalah seluruh kepala keluarga masyarakat Kayu Merah Kota Ternate dengan besar sampel yang digunakan adalah 88 KK (kepala keluarga).Hasil penelitian yang dilihat dari uji Chi-square diperoleh distribusi tidak bermakna antara pengetahuan $(\rho=0,754>0,1)$ tingkat pendidikan $(\rho=0,988>0,1)$, dan keterpaparan media ( $\rho=0,710>0,1)$ dengan stigma terhadap ODHA (orang dengan HIV dan AIDS). Berdasarkan hasil penelitian ini diharapkan kepada instansi Puskesmas setempat perlu meningkatkan promosi tentang HIV dan AIDS, dan penanggulangan preventif atau peraturan dari pemerintah pusat dan daerah dalam bentuk UU serta adanya kontrol masyarakat terhadap hukum yang berkaitan perzinaan (seks bebas) dan kepada peneliti selanjutnya sebaiknya mengmbil variabel selain dari penelitian ini yakni variabel interaksi dengan ODHA dan pemberian label negatif misalnya penyakit kutukan.
\end{abstract}

Keyword: HIV, AIDS, Stigma, ODHA

\section{PENDAHULUAN}

HIV/AIDS telah menjadi pandemik dan masalah kesehatan diseluruh dunia. Prevalensi HIV/AIDS di seluruh dunia terus mengalami peningkatan. Berdasarkan United Nations Programme on HIV/AIDS (UNAIDS) Global Statistics Pada tahun 2018 tercatat 36,9 juta orang di dunia hidup dengan HIV, dengan 35,1 juta orang dewasa di dunia hidup dengan HIV dan 1,8 juta anak-anak $(<15$ tahun).Terdapat 1,8 juta orang menjadi terinfeksi HIV baru.Orang yang hidup dengan HIV (ODHA)dari 75\% mengetahui status HIV mereka dan sekitar 9,4 juta orang tidak tahu bahwa mereka hidup dengan HIV, dan 940.000 orang meninggal karena penyakit terkait AIDS (Data UNAIDS, 2018)

Berdasarkan UNAIDSGlobal Statistics pada tahun 2018 menurut wilayah orang yang hidup dengan HIV tertinggi menduduki posisi pertama yakni di wilayah Afrika Timur dan Selatantercatat 19,6 juta penderita. Posisi kedua adalah kawasan Afrika Barat dan Tengah dengan angka 6,1 juta pengidap. Posisi ketiga adalah Asia Pasifik tercatat 5,2 juta penderita. Indonesia menjadi salah satu negara yang termasuk dalam Kawasan Asia Pasifik.Angka penderita di Indonesia menyumbang sebesar 620.000 dari total 5,2 juta jiwa di Asia Pasifik yang terjangkit HIVdan AIDS. Jika dikelompokkan berdasarkan latar belakangnya, penderita HIV/AIDS datang dari kalangan pekerja 
seks komersial (5,3 persen), homoseksual (25,8 persen), pengguna narkoba suntik (28,76 persen), transgender (24,8 persen), dan mereka yang ada di tahanan (2,6 persen)(Data UNAIDS, 2018).

Laporan situasi perkembangan HIV-AIDS dan IMS (Infeksi Menular Seksual) di Indonesia jumlah Infeksi HIV dan AIDS tahun 2009 sampai dengan 2017 yang terinfeksi HIV berjumlah 280.623 sedangkan yang menderita AIDS berjumlah 102.667. Untuk provinsi Maluku Utara dari tahun 2009 sampai dengan 2017 terinfeksi HIV berjumlah 579 orang sedangkan penderita AIDS 529 jiwa (Ditjen P2p Kementerian Kesehatan RI, 2017).

Distribusi kasus HIV dan AIDS Kota Ternate semakin meningkat pertahunnya. Pada tahun 2016 penderita HIV sebanyak 33 orang sedangkan AIDS adalah 27 orang, pada tahun 2017 penderita HIV sebanyak 22 orang sedangkan AIDS adalah 23 orang. Pada tahun 2018 penderita HIV sebanyak 45 orang sedangkan AIDS adalah 15 orang. Sedangkan untuk jumlah kasus HIVtertinggi berdasarkan puskemas Kota Ternate tahun 2018 tertinggi pada Puskesmas Kalumata dengan penderita 26 kasus. Untuk distribusi jumlah kasus HIV tertinggi menurut Kelurahan yakni pada Kelurahan Kalumata dengan jumlah penderita yakni 8 orang dan Kelurahan Kayu Merah yakni 4 orang (Data Dinas Kesehatan Kota Ternate, 2018)

ODHA adalah Orang Dengan HIV dan AIDS. ODHA adalah orang yang telah terinfeksi virus HIV (Permenkes RInomor 87 tahun 2014). Stigma terhadap ODHA adalah suatu sifat yang menghubungkan seseorang yang terinfeksi HIV dengan nilai-nilai negatif yang diberikan oleh mereka (masyarakat). Stigma membuat ODHA diperlakukan secara berbeda dengan orang lain. Diskriminasi terkait HIV adalah suatu tindakan yang tidak adil pada seseorang yang secara nyata atau diduga mengidap HIV (Harek, 2002).

Sejumlah survei rumah tangga melaporkan meluasnya sikap menstigma terhadap ODHA diantara masyarakat umum di semua sampel yang diteliti pada keadaan yang berbeda seperti China, US, Hong Kong, Afrika Selatan, Jamaica, Brazil, Nigeria, Thailand, Tanzania, Zimbabwe, Burkina Faso, Zambia, dan Ghana.Salah satu penelitian di Iran menemukan prevalensi stigma dan persepsi negatif terhadap ODHA berkisar 46-69\%. Di Indonesia terdapat sekitar 62,8\% laki-laki dan perempuan berusia 15-49 tahun yang mendiskriminasi terhadap ODHA. Analisis Riset Kesehatan Dasar (Riskesdas) dan Survei Sosial Ekonomi Nasional (Susenas) 2007 mengukur sikap stigma dengan empatpertanyaan yaitu 1) setuju atau tidak tentang merahasiakan, membicarakan dengan anggota keluarga lain, 2) konseling dan pengobatan, 3) mencari pengobatan alternatif, dan 4) mengucilkan bila ada anggota keluarga yang menderita HIV/AIDS. Hasil penelitian menunjukkan $62,7 \%$ responden memperlihatkan sikap yang tidak setuju sehubungan dengan penyakit AIDS (Situmeang,2017).

Stigma terhadap HIV telah menurun di sebagian besar wilayah sejak tahun 2000, tetapi tetap tinggi di beberapa negara. Lebih dari setengah dari responden survei rumah tangga di Komoro dan Ethiopia mengatakan mereka akan menghindari membeli sayuran dari penjual yang hidup dengan HIV. Sikap diskriminatif ini juga dinyatakan oleh 31\% dari orang-orang di Angola, 25\% di Uganda, 21\% di Mozambik, 18\% di Zimbabwe, 15\% di Malawi dan 13\% di Botswana, menunjukkan bahwa banyak orang masih kurangnya pengetahuan dasar tentang HIV. Di Uganda, hampir dua pertiga (64\%) orang-orang yang disurvei yang menggunakan narkoba mengatakan mereka menghindari layanan kesehatan karena takut diskriminasi atau dilaporkan kepihak penegak hukum (Data UNAIDS 2018).

Stigma dan diskriminasi terhadap ODHA dipengaruhi oleh beberapa faktor seperti pengetahuan, persepsi, pendidikan, jenis kelamin, umur, status ekonomi, keterpaparan sumber informasi tentang HIV dan AIDS, serta adanya interaksi dengan ODHA juga mempengaruhi stigma seseorang terhadap ODHA. Di indonesia, penelitian yang dilakukan oleh Febrianti tahun 2016, hasil penelitiannya diperoleh proporsi remaja yang memiliki stigma berat terhadap ODHA berjumlah 148 $(69,8 \%)$, ada kecenderungan pengetahuan rendah, persepsi negatif, tidak pernah berinteraksi dengan ODHA dan status ekonomi keluarga rendah memiliki stigma berat terhadap ODHA.

Penelitian yang dilakukan olehHati (2013) hasilnya diperoleh Sikap masyarakat Kota Kupang terhadap ODHA masih dikategorikan baik walaupun terdapat $44.0 \%$ responden yang memberikan stigma tinggi, dan masih terdapat stigma sebesar $26.1 \%$ di keluarga, $19.1 \%$ di tempat kerja, 55.8\% di yankes, $23.3 \%$ di masyarakat dan $29.3 \%$ di sekolah. Sebesar $37.7 \%$ responden mengatakan bahwa ODHA seharusnya diisolasi bila dirawat di rumah sakit, sebesar $38.2 \%$ perawatan terhadap ODHA harus menggunakan perlindungan yang ekstra, sebesar $55.8 \%$ mengatakan bahwa tindakan isolasi ODHA itu merupakan keputusan yang paling tepat agar bisa membedakan penderita HIV dengan 
penderita lain. Penelitian oleh Wahyunitahun (2016) hasil penelitiannya menunjukkan ada hubungan yang bermakna namun negatif antara pengetahuan HIV/AIDS dengan sikap.Dan variabel yang secara substansial menjadi confounder adalah tingkat pendidikan dan keterpaparan media.Selain itu, terdapat interaksi antara pengetahuan dengan tingkat pendidikan serta pengetahuan dengan keterpaparan media.

Pada Evaluasi Kinerja SPM-BK Tahun 2013 berdasarkan wilayah puskesmas di Kota Ternate tahun 2014, ada pun masih adanya stigma dan diskriminasi ODHA yang merupakan salah satu kendala dalam pengendalian penyakit HIV/AIDS di kota Ternate yang tertuang pada program IMS, HIV DAN AIDS (Dinkes Kota Ternate 2014).

Berdasarkan wawancara awal kepada konselor HIV dan AIDS di puskesmas Kalumata masih adanya stigma negatif dari masyarakat Kayu Merah terhadap ODHA yang terlihat pada kasus pengusiran kepada salah satu warga ibu hamil "S" oleh keluarga yang mendengar bahwa pendeita menderita HIV pada tahun 2016. Kelurahan kayu merah memiliki jumlah penduduk sebanyak 6282 jiwa, dengan jumlah laki-laki adalah 3014 jiwa dan perempuan adalah 3268 jiwa. Dan memiliki jumlah KK adalah 1250 jiwa (Data jumlah penduduk Kayu Merah tahun 2018)

\section{METODOLOGI PENILITIAN}

Jenis penelitian yang digunakan adalah penelitian Survey Analitik dengan rancangan "Cross Sectional Study". Penelitian ini dilaksanakan pada bulan Agustus tahun 2019 dengan lokasi penelitian di wilayah Kelurahan Kayu Merah Kota Ternate Selatan. Populasi penelitian ini adalah seluruh KK (kepala keluarga) dengan jumlah 764kepala keluarga yang terdata di Kelurahan Kayu Merah Kota Ternate Selatan tahun 2019. Sampel pada penelitian ini adalah sebagian dari populasi yakni 88 responden yang diambil secara random sampling.

\section{HASIL DAN PEMBAHASAN}

\subsection{Hasil}

\subsection{Analisis Univariat}

Tabel 1. Distribusi Responden berdasarkan Stigma terhadap ODHA dikeluarahan kayu merah Kota Ternate Tahun 2019

\begin{tabular}{ccc}
\hline Stigma terhadap ODHA & $\mathbf{N}$ & $\mathbf{\%}$ \\
\hline Stigma berat & 17 & 19,3 \\
Stigma ringan & 71 & 80,7 \\
\hline Total & $\mathbf{8 8}$ & $\mathbf{1 0 0}$
\end{tabular}

Sumber : Data Primer Tahun 2019

Tabel 1 diatas menunjukkan bahwa distribusi responden berdasarkan stigma terhadap ODHA dari 88 responden stigma berat berjumlah 17 (19,3\%) responden dan stigma ringan berjumlah 71 $(80,7 \%)$ responden

\subsection{Anallisis Bivariat}

Tabel 2. Hubungan antara pengetahuan HIV dan AIDS dengan stigma terhadap orang dengan HIV dan AIDS (ODHA) Di Kelurahan Kayu Merah Kota Ternate Tahun 2019

\begin{tabular}{|c|c|c|c|c|c|c|c|}
\hline \multirow{3}{*}{ Pengetahuan } & \multicolumn{4}{|c|}{ Stigma terhadap odha } & \multirow{2}{*}{\multicolumn{2}{|c|}{ Total }} & \multirow{3}{*}{ '-Value } \\
\hline & \multicolumn{2}{|c|}{ Stigma berat } & \multicolumn{2}{|c|}{ Stigma ringan } & & & \\
\hline & $\mathbf{N}$ & $\%$ & $\mathbf{N}$ & $\%$ & $\mathbf{N}$ & $\%$ & \\
\hline Baik & 8 & 9,1 & 39 & 44,3 & 47 & 53,4 & \multirow{3}{*}{0,754} \\
\hline Kurang & 9 & 10,2 & 32 & 36,4 & 41 & 6 & \\
\hline Jumlah & 17 & 19,3 & 83 & 80,7 & 88 & 100 & \\
\hline
\end{tabular}

Sumber : Data Primer Tahun 2019 
Tabel 2 diatas menunjukkan bahwa dari 47 respondenyang memiliki pengetahuan baik terdapat $8(9,1 \%)$ responden dengan stigma berat dan $39(44,3 \%)$ responden berstigma ringan, sedangkan dari 41 responden memiliki pengetahuan kurang terdapat $9(10,2 \%)$ responden dengan stigma berat dan $32(36,4 \%)$ responden berstigma ringan.

Dari hasil uji statistic Chi-square diperoleh nilai $\rho=0,754>0,1$ sehingga Hipotesis Ho diterima yang berarti tidak ada hubungan antara pengetahuan dengan stigma terhadap ODHA (orang dengan HIV dan AIDS).

Tabel 3. Hubungan antara tingkat pendidikan dengan stigma terhadap orang dengan HIV dan AIDS (ODHA) Di Kelurahan Kayu Merah Kota Ternate Tahun 2019

\begin{tabular}{|c|c|c|c|c|c|c|c|}
\hline \multirow{3}{*}{ Tingkat Pendidikan } & \multicolumn{4}{|c|}{ Stigma terhadap ODHA } & \multirow{2}{*}{\multicolumn{2}{|c|}{ Total }} & \multirow{3}{*}{ P-Value } \\
\hline & \multicolumn{2}{|c|}{ Stigma berat } & \multicolumn{2}{|c|}{ Stigma ringan } & & & \\
\hline & $\mathrm{N}$ & $\%$ & $\mathbf{N}$ & $\%$ & $\mathbf{N}$ & $\%$ & \\
\hline Tinggi & 13 & 14,8 & 57 & 64,8 & 70 & 79,5 & \multirow{3}{*}{0,743} \\
\hline Rendah & 4 & 4,5 & 14 & 15,9 & 18 & 20,5 & \\
\hline Jumlah & 17 & 19,3 & 71 & 80,7 & 88 & 100 & \\
\hline
\end{tabular}

Sumber : Data Primer Tahun 2019

Tabel 3 diatas menunjukkan bahwa dari 70 responden yang memiliki tingkat pendidikan tinggi terdapat $13(14,8 \%)$ responden dengan stigma berat dan $57(64,8 \%)$ responden berstigma ringan, sedangkan dari 18 responden dengan tingkat pendidikan rendah terdapat $4(4,5 \%)$ responden berstigma berat dan $14(15,9 \%)$ responden berstima ringan.

Dari hasil uji statistic Chi-square dengan nilai fisher's exact test diperoleh nilai $\rho=0,743>0,1$ sehingga Hipotesis Ho diterima yang berarti tidak ada hubungan antara tingkat pendidikan dengan stigma terhadap ODHA (orang dengan HIV dan AIDS)

Tabel 4. Hubungan antara keterpaparan media dengan stigma terhadap orang dengan HIV dan AIDS (ODHA) Di Kelurahan Kayu Merah Kota Ternate Tahun 2019

\begin{tabular}{|c|c|c|c|c|c|c|c|}
\hline \multirow{3}{*}{ Terpaparan media } & \multicolumn{4}{|c|}{ Stigma terhadap odha } & \multirow{2}{*}{\multicolumn{2}{|c|}{ Total }} & \multirow[b]{2}{*}{ P-Value } \\
\hline & \multicolumn{2}{|c|}{$\begin{array}{c}\text { Stigma } \\
\text { berat }\end{array}$} & \multicolumn{2}{|c|}{$\begin{array}{l}\text { Stigma } \\
\text { ringan }\end{array}$} & & & \\
\hline & $\mathrm{N}$ & $\%$ & $\mathrm{~N}$ & $\%$ & $\mathrm{~N}$ & $\%$ & \multirow{4}{*}{0,710} \\
\hline Terpapar media & 14 & 15,9 & 61 & 69,3 & 75 & 85,2 & \\
\hline Kurang terpapar media & 3 & 3,4 & 10 & 11,4 & 13 & 14,8 & \\
\hline Jumlah & 17 & 19,3 & 71 & 80,7 & 88 & 100 & \\
\hline
\end{tabular}

Sumber : Data Primer Tahun 2019

Tabel 4 diatas menunjukkan bahwa dari 75 respondenyang terpapar media terdapat 14 $(15,9 \%)$ responden dengan berstigma berat dan $61(69,3 \%)$ responden dengan berstigma ringan, sedangkan dari 13 responden kurang terpapar media terdapat 3(3,4\%) responden berstigma berat dan $10(11,4 \%)$ responden berstigma ringan.

Dari hasil uji statistikChi-square dengan nilai fisher's exact test diperoleh nilai $\rho=0,710>0,1$ sehingga Hipotesis Ho diterima yang berarti tidak ada hubungan antara tingkat pendidikan dengan stigma terhadap ODHA (orang dengan HIV dan AIDS).

\subsection{Pembahasan}

\subsubsection{Hubungan pengetahuan HIV dan AIDS dengan stigma terhadap orang dengan HIV dan AIDS (ODHA)}

Menurut Notoatmodjo (2007) mendefinisikan pengetahuansebagai hasil dari tahu setelah seseorang melakukan penginderaanterhadap suatu objek tertentu melalui indera penglihatan, pendengaran,penciuman, rasa, dan raba. Sebagian besar pengetahuan merupakan hal yang sangat utuh terbentuknya tindakan seseorang.

Berdasarkan hasil penelitian dan pengolahan data yang telah dilakukan terhadap responden di wilayah Kelurahan Kayu Merah menunjukkan bahwa dari 47 responden yang memiliki pengetahuan baik terdapat $8(9,1 \%)$ responden dengan stigma berat dan $39(44,3 \%)$ responden berstigma ringan, 
sedangkan dari 41 responden memiliki pengetahuan kurang terdapat $9(10,2 \%)$ responden dengan stigma berat dan $32(36,4 \%)$ responden berstigma ringan.

Dari hasil uji statistikChi-square diperoleh nilai $\rho=0,754>0,1$ sehingga Hipotesis Ho diterima yang berarti tidak ada hubungan antara pengetahuan dengan stigma terhadap ODHA (orang dengan HIV dan AIDS).

Hasil penelitian ini sesuai dengan penelitian Saluhiyah Zohra dkk (2015) di Kelurahan Brobongan Jawa Tengah yang mengemukakan bahwa pengetahuan tentang IMS (infeksi menular seksual) dan HIV/AIDS HIV/AIDS tidak memiliki hubungan bermakna dengan stigma terhadap ODHA dengan nilai $\rho=0,638>0,05$ yang memiliki pengetahuan baik adalah sebanyak $67(47,9 \%)$ responden dengan berstigma dan tidak berstigma adalah $73(52,1 \%)$ sedangkan pengetahuan kurang adalah sebanyak $82(51,3 \%)$ responden berstigma dan tidak berstigma $78(48,8 \%)$ responden. Dan tidak sejalan dengan penelitian situmeang (2017) mengemukakan bahwa pengetahuan tentang HIV/AIDS HIV/AIDS memiliki hubungan bermakna dengan stigma terhadap ODHA dengan nilai $\rho=0,000>0,05$, memiliki pengetahuan cukup $2.741(64,75)$ dengan berstigma berat dan tidak berstigma $867(21,23 \%)$ responden, memiliki pengetahuan kurang dengan berstigma berat $3.216(78,77 \%)$ responden dan tidak berstigma $1.492(35,25 \%)$ responden.

Penelitian ini dengan perbandingan kedua penelitian yang membedakan adalah jumlah sampel yang dimiliki Situmeang (2017) lebih banyak dengan sampel 8.316 responden,daripada penelitian ini dengan sampel 88 responden danSaluhiyah Zohra dkk (2015) dengan sampel 300 responden, sehingga penelitian Situmeang ada hubungan antara pengetahuan dan stigma terhadap ODHA sedangkan penelitian ini dan Saluhiyah Zohra dkk tidak memiliki hubungan penegtahuan dengan stigma terhadap ODHA.

Seseorang yang memiliki tingkat pengetahuan baik dapat mengurangi stigma yang diberikan oleh masyarakat terhadap ODHA.Sebagian masyarakat memiliki tingkat pengetahuan yang baik namun masih memberikan stigma berat karna dipengaruhi oleh persepsi salah terhadap ODHA yang mengetahui biasanya menular melalui hubungan seks sehingga ODHA harus diusir dari rumah karena perilaku yang buruk dengan dihubungkan dengan penyakit kutukan akibat dari freeseks misalnya PSK.Meskipun demikian perilaku dan infeksi HIV dan ODHA tidak ada kaitannya dilihat dari sisi penularannya.

\subsubsection{Hubungan tingkat pendidikandengan stigma terhadap orang dengan HIV dan AIDS (ODHA)}

Menurut Azyumardi Azra, (2005) Pendidikan adalah usaha sadar dan terencana untuk mewujudkan suasana belajar dan proses pembelajaran agar peserta didik secara aktif mengembangkan potensi dirinya untuk memiliki kekuatan spiritual keagamaan, mengendalikan diri, kepribadian, kecerdasan, akhlak mulia, serta keterampilan yang diperlukan dirinya, masyarakat, bangsa dan negara (Tatang, 2016).

Berdasarkan hasil penelitian dan pengolahan data yang telah dilakukan terhadap responden KK (kepala keluarga) di Wilayah Kelurahan Kayu Merah menunjukkan bahwa dari 70 responden yang memiliki tingkat pendidikan tinggi terdapat $13(14,8 \%)$ responden dengan stigma berat dan 57 $(64,8 \%)$ responden berstigma ringan, sedangkan dari 18 responden dengan tingkat pendidikan rendah terdapat $4(4,5 \%)$ responden berstigma berat dan $14(15,9 \%)$ responden berstima ringan.

Dari hasil uji statistikChi-square dengan nilai fisher's exact test diperoleh nilai $\rho=0,743>0,1$ sehingga Hipotesis Ho diterima yang berarti tidak ada hubungan antara tingkat pendidikan dengan stigma terhadap ODHA (orang dengan HIV dan AIDS).

Hasil penelitian inisesuai dengan penelitian oleh Retnowati (2012) Berdasarkan hasil penelitian ditunjukkan bahwa Tokoh agama yang melakukan stigma terhadap ODHA di Kabupaten Banyumas lebih banyak dijumpai pada kelompok yang berpendidikan menengah (56,9\%) dibandingkan dengan kelompok berpendidikan tinggi $(48,1 \%)$ dan nilai $\rho=0,401>0,05$. Hal ini membuktikan bahwa tidak ada hubungan pendidikan dengan stigma tokoh agama terhadap ODHA.

Hasil penelitian ini tidak sesuai dengan penelitian oleh Wahyuni dan Ronoadmodjo(2016) yang mengemukakan bahwa pendidikan berhubungan dengan penolakan (stigma) terhadap ODHA yakni memiliki hubungan bermakna dengan nilai $\rho=0,001<0,05$ yang memiliki pendidikan baik dengan penolakan (stigma) pada ODHA (69,90 \%)dan pendidikan kurang dengan menerima (tidak berstigma) pada ODHA(30,1 \%).Sehingga antara penelitian ini dengan perbandingan kedua penelitian 
yang membedakan adalah jumlahnya, jumlah sampel ini dengan Retnowati berjumlah lebih sadikit daripada Wahyuni yang lebih banyak, yakni pada penelitian ini adalah 88 responden, Retnowati (2012) yakni berjumlah 164 responden dan Wahyuni (2012) berjumlah 41.004 responden.

Tingkat pendidikan seseorang dapat mempengaruhi stigma yang diberikan terhadap ODHA. Semakin tinggi tingkat pendidikan masyarakat maka akan memberikan stigma ringan terhadap ODHA.Menurut Wawan dalam Retnowati (2012).Tingkat pendidikan sangat menentukan daya nalar seseorang yang lebih baik, sehingga memungkinkan menyerap informasi-informasi juga dapat berpikir secara rasional dalam menanggapi informasi atas setiap masalah yang dihadapi.

\subsubsection{Hubungan Keterpaparan media dengan stigma terhadap orang dengan HIV dan AIDS (ODHA)}

Menurut Mc.Lukman menguraikan bahwa media secara umum adalah perpanjangan alat indra manusia. Dengan media kita memperoleh informasi tentang benda, orang, dan tempat yang tidak kita pahami secara langsung. Dunia ini terlalu luas untuk kita masuki semuanya, dan media massa datang menyampaikan berbagai pesan tentang lingkungan sosial dan politik.

Berdasarkan hasil penelitian dan pengolahan data yang telah dilakukan terhadap responden KK (kepala keluarga) di Wilayah Kelurahan Kayu Merah menunjukkan bahwa distribusi responden menurut keterpaparan media menunjukkan bahwa dari 75 responden yang terpapar media terdapat $14(15,9 \%)$ responden dengan berstigma berat dan $61(69,3 \%)$ responden dengan berstigma ringan, sedangkan dari 13 responden kurang terpapar media terdapat $3(3,4 \%)$ responden berstigma berat dan $10(11,4 \%)$ responden berstigma ringan.

Dari hasil uji statistikChi-square dengan nilai fisher's exact test diperoleh nilai $\rho=0,710>0,1$ sehingga Hipotesis Ho diterima yang berarti tidak ada hubungan antara tingkat pendidikan dengan stigma terhadap ODHA (orang dengan HIV dan AIDS).

Hasil penelitian ini tidak sesuai dengan penelitian oleh Wahyuni dan Ronoadmodjo (2016) yang mengemukakan bahwa keterpaparan media berhubungan dengan penolakan (stigma) terhadap ODHA artinya memiliki hubungan bermakna dengan nilai $\rho=0,001<0,05$ yang memiliki Kurang terpapar media $71,05 \%$ dengan penolakan (berstigma) $28,9 \%$ dan terpapar media 57,29\% dengan penerimaan (tidak berstigma) 42,7 \%.

Hasil penelitian ini juga tidak sesuai dengan penelitian oleh Tianingrum (2018) Hasil uji hubungan antara keterpaparan informasi dengan stigma terhadap ODHA menunjukkan bahwa persentase stigma terhadap ODHA pada pelajar yang tidak terpapar informasi mengenai HIV\&AIDS $(67,3 \%)$ lebih tinggi dibandingkan pelajar yang terpapar $(48,2 \%)$. Hasil uji statistik didapatkan pvalue sebesar 0,0001 , artinya ada hubungan yang signifikan antara keterpaparan informasi tentang HIV dan AIDS dengan stigma terhadap ODHA. Artinya pelajar yang tidak terpapar informasi mengenai HIV dan AIDS memiliki peluang lebih besar untuk melakukan stigma terhadap ODHA dibandingkan pelajar yang terpapar.

Sampel penelitian ini memiliki jumlah sampel 88 responden, Tianingrum 785 responden dan Wahyuni 41.004 responden. Sampel dari ketiga penelitian di atas memiliki perbedaan jumlah sampel, Sehingga antara penelitian ini dan kedua penelitian di atas tidak ada perbedaan jumlah besar atau kecilnya sampel yang dapat mempengaruhi tidak bermaknanya atau tidak hubungan antara keterpaparan media dengan sirma terhadap ODHA.

Keterpaparan media sangat berpengaruh dalam mengubah persepsi seseorang terutama masyarakat, karena itu sumber media yang didapatkan oleh masyarakat haruslah benar dan semaksimal mungkin mendapatkan informasi HIV dan AIDS melalui berbagai sumber informasi (media), sehingga dapat mengurangi dan meringankan stigma terhadap ODHA.Hasil penelitian ini juga menunjukkan bahwa sumber informasi yang paling sering didapatkan oleh masyarakat adalah ketika dahulu bersekolah dan melalui media televisi dengan presentase $(76,1 \%)$, sehingga sumber media ini memegang peranan penting dalam penyampaian informasi.

\subsubsection{Stigma terhadap orang dengan HIV dan AIDS (ODHA)}

Stigma adalah pandangan negatif yang ditujukan kepada ODHA.Stigma ringan jikalau responden memiliki $>75 \%$, sebaliknya dikatakan stigma berat jika responden $<75 \%$.Stigma terhadap ODHAmerupakan variabel dependen (variabel terikat) yang dipengaruhi oleh variabel bebas (independen), Semakin seseorang memiliki pengetahuan baik, tingkat pendidikan yang tinggi dan terpapar media, maka semakin ringan stigma yang diberikan terhadap ODHA. Sebaliknya seseorang 
memiliki pengetahuan kurang, tingkat pendidikan yang rendah dan kurang terpapar media, maka semakin berat stigma terhadap ODHA. Distribusi responden berdasarkan stigma terhadap ODHA dari 88 responden stigma berat berjumlah $17(19,3 \%)$ responden dan stigma ringan berjumlah $71(80,7 \%)$ responden.

Hasil penelitian ini terhadap Beberapa respondenmasih memberi stigma berat terhadap pertanyaan anggota keluarga yang tertular HIV/AIDS akan merahasiakan dengan jumlah yang menjawab tidak setuju $(78,4 \%)$, setuju $(13,6 \%)$ dan sangat setuju $(8,0 \%)$. Hal ini kemungkinan disebabkan mereka khawatir jika status HIV positif anggota keluarganya diketahui orang lain akan menunjukkan beragam perlakuan tidak adil terhadap mereka seperti dijauhi dan diejek sampai dengan pembatasan hak mereka. Penelitian ini memiliki pertanyaan sama hal dengan Situmeang (2017) yang menyatakan Lebih dari setengah responden akan merahasiakan anggota keluarga yang tertular HIV $(57,8 \%)$.

Beberapa responden masih memberi stigma berat terhadap pertanyaan tidak akan membeli sayuran segar dari penjual atau petani yang diketahui terinfeksi HIV/AIDS dengan jumlah yang menjawab bahwa tidak setuju $(72,7)$ setuju $(17,0 \%)$ responden dan sangat setuju $(10,2 \%)$. Penelitian ini memiliki pertanyaan sama hal dengan Situmeang (2017) diketahui bahwa 66,6\% responden tidak akan membeli sayuran segar dari penjual atau petani yang diketahui terinfeksi HIV/AIDS. Seperti diketahui orang yang terinfeksi HIV (penjual sayuran) akan mengalami infeksi oportunistik yang terkait dengan infeksi HIV. Hal ini kemungkinan yang menyebabkan orang enggan membeli sayuran karena takut tertular infeksi tersebut.

Beberapa responden masih memberi stigma berat terhadap pertanyaanterhadap menjahuiorang pemakai narkoba karna bisa tertular dengan jumlah yang menjawab tidak setuju $(37,5 \%)$ setuju $(28,4 \%)$ dan sangat setuju $(34,1,5 \%)$. Hal ini kemungkinan disebabkan mereka memiliki pemahaman yang salah berkaitan dengan penularan HIV/AIDS karna penularan HIV/AIDS tidak menular ketika berinteraksi dengan mereka tetapi ketika berinteraksi dengan jarum suntik bergantian dengan penderita.

Beberapa responden masih memberi stigma berat terhadap pertanyaan terhadap ODHA tidak boleh hidup ditegah-tengah masyarakat karna mempunyai perilaku buruk dengan jumlah yang menjawab tidak setuju $(65,9 \%)$ setuju $(21,6 \%)$ dan sangat setuju $(12,5 \%)$. Hal ini kemungkinan disebabkan mereka memiliki pemahaman yang salah berkaitan dengan penularan HIV/AIDS karna penularan HIV/AIDS tidak menular ketika berinteraksi dengan ODHA yang memiliki perilaku buruk dalam bergaul tetapi berinteraksi dengan sumber penularannya.

Hasil penelitian ini terhadap beberapa responden masih memberi stigma berat terhadap pertanyaan terhadap ODHA harus diusir dari lingkungan tempat tinggalnya dengan jumlah yang menjawab tidak setuju $(75,0 \%)$ setuju $(23,9 \%)$ dan sangat setuju $(1,1 \%)$. Hal ini disebabkan mereka memiliki pemahaman yang salah berkaitan dengan penularan HIV/AIDS yakni ketika mereka berinteraksi dengan ODHA maka dapat tertular baik melalui interaksi pada saat kegiatan gotong royong, berjabat tangan dan saat berbicara, persepsi yang salah semacam ini sehingga beberapa responden masih memberikan stigma.

Hasil penelitian ini terhadap beberapa responden masih memberi stigma berat terhadap pertanyaan memusuhi ODHA yang pasti menularkan HIV dan AIDS akibat dari tingkah lakunya yang buruk misalkan suka bergaul dengan pekerja seks komersial jumlah yang menjawab tidak setuju $(65,9 \%)$ setuju $(22,7 \%)$ dan sangat setuju $(11,4 \%)$. Hal ini disebabkan mereka memiliki pemahaman yang salah berkaitan dengan penularan HIV/AIDS yakni ketika mereka berinteraksi dengan ODHA yang memiliki pekerjaan PSK (pekerja seks komersial) maka dapat tertular.Namun dapat tertular HIV dan AIDS melalui hubungan seksual dengan pengidap HIV/AIDS, kotak langsung dengan darah (tranfusi darah yang tercemar HIV dan pemakaian jarum suntik yang tidak steril/memakai bersama dengan pendita HIV) dan menular melalaui ibu kepada bayi.

Hasil penelitian ini terhadap beberapa responden masih memberi stigma berat terhadap pertanyaan mengetahui suami/istri/keluarga terinfeksi HIV segera mengusirnya dari rumahdengan jumlah yang menjawab tidak setuju $(84,1, \%)$ setuju $(13,6 \%)$ dan sangat setuju $(2,3 \%)$. Hal ini disebabkan mereka memiliki pemahaman yang salah berkaitan dengan penularan HIV/AIDS yakni ketika mereka berinteraksi dengan ODHA maka dapat tertular baik memakai peralatan makan bersama, peralatan mandi bersama dan berinteraksi dengan pengidap HIV dan AIDS. 
Hasil penelitian ini terhadap beberapa responden masih memberi stigma berat terhadap pertanyaan ODHA harus dikeluarkan dari kegiatan dan pekerjaan ditegah-tengah masyarakat dengan jumlah yang menjawab tidak setuju $(67,0 \%)$ setuju $(22,7 \%)$ dan sangat setuju $(10,2 \%)$. Hal ini disebabkan mereka memiliki pemahaman yang salah berkaitan dengan penularan HIV/AIDS yakni ketika mereka berinteraksi dengan ODHA maka dapat tertular dan mengganggapnya sebagai penyakit kutukan sehingga harus diusir ditegah-tegah masyarakat.

Beberapa responden yang memiliki kepercayaan bahwa HIV/AIDS merupakan penyakit kutukan sehingga harus diusir dari rumah, diasingkan ditengah-tengah masyarakat, tidak boleh bergaul dengan yang terinfeksi (ODHA) dan bahkan memusuhi mereka. Permasalahan sosial seperti penerimaan label negatif dan berbagai bentuk diskriminasi dari lingkungan misalkan pada pemberian label oleh salah satu responden penyakit kutukan akibat dari perbuatan menyimpang seperti PSK (Pekerja seks komersial), gey, pelaku seks bebas dan penggunaan narkoba suntik yang dianggap sebagai pembawa penyakit HIV/AIDS sehingga mendapati stigma berat dan deskriminasi yang mematikan dikalangan masyarakat (Sarikusuma, 2012).

Seseorang memiliki tingkat pengetahuan tinggi, pendidikan tinggi dan terpapar media namun masih memiliki stigma berat, sesuai dengan hasil stigma terhadap ODHA dari 88 responden stigma berat berjumlah 17 (19,3\%) responden dan stigma ringan berjumlah 71 (80,7\%) responden, Artinya sama saja ketika seseorang berpengetahuan baik dan kurang tidak memberikan stigma berat terhadap ODHA. Dan seseorang memiliki pendidikan tinggi dan rendah tidak mempengaruhi stigma berat.Sama halnya dengan seseorang yang terpapar media dan kurang terpapar tidak mempengaruhi stigma barat sehingga ketiganya variabel di atas memberikan stigama ringan.

\section{PENUTUP}

\subsection{Kesimpulan}

Berdasakan hasil penelitian tentang stigma terhadap orang dengan HIV dan AIDS (ODHA) pada masyarakat di Kelurahan Kayu Merah Kota Ternate tahun 2019 dapat disimpulakn bahwa :

1. Tidak ada hubungan antara pengetahuan HIV dan AIDS dengan stigma terhadap orang dengan HIV dan AIDS (ODHA) diperoleh nilai ( $\rho=0,754>0,1)$.

2. Tidak ada hubungan antara tingkat pendidikan dengan stigma terhadap orang dengan HIV dan AIDS (ODHA) diperoleh nilai $(\rho=0,743>0,1)$.

3. Tidak ada hubungan antara keterpaparan media dengan stigma terhadap orang dengan HIV dan AIDS (ODHA)diperoleh nilai $(\rho=0,710>0,1)$.

\subsection{Saran}

Berdasarkan hasil analisis, maka saran yang dapat disampaikan yaitu :

1. Untuk Puskesmas setempat perlu meningkatkan promosi tentang HIV dan AIDS karena kalaupun sudah tidak ada stigma sesuai dengan variabel yang diteliti tetapi lebih memaksimalkan lagi sehingga dapat menambah pengetahuan masyarakat tentang pentingnya mengetahui HIV dan AIDS dari kesalahan-kesalahan persepsi yang salah sehingga tidak mengurangi dan bahkan tidak ada lagi stigma ditegah-tengah masyarakat khususnya Kelurahan Kayu Merah dan masyarakat umumnya yakni masyarakat Maluku utara dan tentunya Indonesia negeri tercinta ini.

2. Perlu adanya advokasi lintas sektor lembaga kesehatan, tokoh keagamaan dan lembaga kepemerintahan dalam hal ini Kelurahan untuk membuat kegiatan sosialisasi tentang HIV dan AIDS setiap bulannya, sehingga dapat menekan stigma masyarakat terhadap ODHA..

3. Perlu adanya penanggulangan preventif atau peraturan dari pemerintah pusat dan daerah dalam bentuk UU untuk mengatasi akar masalah (dikhususkan pada penularan lewat hubungan seksual) yakni dengan memberi hukuman kepada siapa saja yang melakukan kemaksiatan dalam hal ini zina yang dilakukan diluar pernikahan dan dalam perselingkuhan dengan status menikah sehingga dapat menekan dan menghapus peningkatan HIV dan AIDS dan disertai kontrol masyarakat terhadap hukum yang berkaitan perzinaan (seks bebas).

4. Kepada peneliti lainyang ingin meneliti stigma terhadap ODHA sebaiknya mengambil variabel selain dari penelitian ini terutama bertempat di Kelurahan Kayu Merah karna dari hasil penelitian tidak memiliki hubungan antara variabel independen dan dependen. Sebaiknya 
meneliti variabel interaksi dengan ODHA, agama dan persepsi negatif (pemberian label terhadap ODHA misalnya penyakit kutukan)

\section{DAFTAR PUSTAKA}

Ardial, 2009, Komunikasi Politik, Jakarta: PT Indeks.

Ditjen P2P Kementerian Kesehatan RI 2017, Laporan situasi perkembangan HIV-AIDS dan IMS tahun 2017, http:// siha. depkes.go.i d/portal/files_upload/Laporan_HIV_A IDSTW_4_Tahun_2017_1_.pdf. Diakses pada tanggal 18-03-2019.

Data UNAIDS 2018, http://www.unaids.org/sites/default/files/media_asset/2017_data-book_en.pdf, Diakses pada tanggal 19-03-2019.

Data UNAIDS 2018, http://www.unaids.org/sites/default/files/media_asset /UNAIDS_FactSheet_en.p df2030 | Mengakhiri epidemic AIDS. Diaksespada tanggal 19-03-2019.

Data DINKES Kota Tenate2018 dan data distrubusi kasus HIV dan AIDS Ternate Tahun 2016-2018.

Evaluasi Kinerja SPM-BK Tahun 2013 Berdasarkan Wilayah Puskesmas di Kota Ternate 2014, https://dinkesternate.files.wordpress.com/2014/04/grafik-dan-petacapaian-spm-bk-berdasarkan-puskesmas-wil-kota-ternate.pdf.Diaksespada tanggal 19-032019.

Febrianti, 2016, Faktor - Faktor Yang Berhubungan Dengan Stigma Terhadap Orang Dengan Hiv Dan Aids (Odha),Journal Endurance,http://ejournal.kopertis10.or. id/index.php/endurance/article/download/1300/ 686. Diakses pada tanggal19-03-2019.

Herek, 2002, HIV Related Stigma and Knowledge in the United States: Prevalence and trends, 19911999. American Journal of Public Health. 2002;92 (3). Horizon. Toolkit on HIV/AIDS. 2012, https://www.ncbi.nlm.nih.gov/pm c/articles/PMC1447082/.Diakses pada tanggal 07-07-2019.

Hati,K., Shaluhiyah, Z., dan Suryoputro, S, 2013, Stigma Masyarakat Terhadap ODHA Di Kota Kupang Provinsi NTT, Jurnal Promosi Promosi Kesehatan Indonesia, Vol.12 ,No.1, https://ejournal.undip.ac.id/index.php/jpki/arti cle/view/18031/12731, Diakses tangal 20-04-19.

Irianto,k, 2014, Epidemiologi Penyakit Menular Dan Tidak Menular Panduan Klinis, Bandung : Alfabeta, $\mathrm{Cv}$

Khrisna, 2016, Studi Cross-Sectional analisis dan studi dalam statistik, http: //datariset.com/analisis/detail/studi-cross-sectional, Diakses pada tanggal 02-04-2019.

Kaputra, et.al,2013, Dampak otonom daerah Di Indonesia : Merangkai sejarah politik dan pemerintahan Indonesia. Jakarta : Yayasan Pustaka Obor Indonesia;

KKBI, 2019, Stigma. https://kbbi.web.id/stigma. Diakses pada tanggal 02-04-2019.

Madjid, erni, 2014, faktor-faktor yang berhubungandengan kunjungan ibuhamil pada antenatal caredi puskesmas kalumata kec.Kotaternate selatan tahun 2014 
Notoatmodjo, S, 2014, Kesehatan Masyarakat Ilmu Dan Seni, Jakarta: PT. Rineka Cipta;

Notoatmodjo, S, 2010, Ilmu Perilaku kesehatan, Jakarta: Rineka Cipta;

Notoatmodjo, S, 2007, Promosi Kesehatan Dan Ilmu Perilaku, Jakarta: Rineka Cipta;

Notoatmodjo,S, 2005, Metodologi Penelitian Kesehatan, Jakarta: PT. Rineka Cipta;

Permenkes RI nomor 87 tahun 2014, tentang pedoman pengobatan antiretroviral, menteri keseh atan republik indonesia, $\mathrm{Http}: / /$ preventcrypto.org/wpcontent/uploads/2015/10/indonesiaa dultartguidelines20141432907982.pdf. Diakses pada tanggal 01-04-2019.

Profil kantor Kelurahan Kayu Merah Kota Ternate Selatan tahun 2019.

Paryati et. al, 2012, Faktor-faktor yang Mempengaruhi Stigma dan Diskriminasi kepada ODHA(Orang dengan HIV/AIDS) oleh petugas kesehatan : kajian literatur, http://pustaka.unpad.ac.id/wp content/uploads/2013/02/Pusta ka_unpad_Faktor_Mempengaruhi_Stigma_ODHApdf.pdf, Diakses tanggal 20-04-19.

Prasetyo, P, Jannah, L, 2012, Metode penelitian kuantitatif: Teori dan Aplikasi, jakarta : Rajawali pers;

Psikologi, 2012, pengertian jenis kelamin, https://www.psychologymania.com/2012/12/pengertianjenis-kelamin.html, Diakses tanggal 28-08-19.

Retnowati, Misrina, Hubungan Pendidikan Dan Kepercayaan Dengan Stigma Tokoh Agama Terhadap Orang Dengan Hiv/Aids (Odha) Di Kabupaten Banyumas, Seminar Nasional dan Presentasi Hasil-Hasil Penelitian Pengabdian Masyarakat, Perwekerto, 2012, ojs. Akbidylpp.ac.id, Diakses pada tanggal 5-09-19.

Situmeang, B, Syarif, S, dan Mahkota, R, 2017, Hubungan Pengetahuan HIV/AIDS $\quad$ dengan Stigma terhadap Orang dengan HIV/AIDS di Kalangan Remaja 15-19 Tahun di Indonesia (Analisis Data SDKI Tahun 2012), jurnal epidemiologi kesehatan indonesia, Vol. 1, No.2, http://journal . fkm. ui. a c. id/epid/article/download/1803/609. Diaksespada tanggal 19-03-2019.

Shaluhiyah, Z., Musthofa, S, Masyarakat terhadap Orang dengan HIV/AIDS, Jurnal B., dan Widjanarko, B, 2014, Stigma Nasional, Vol. 9, No. 4, https://media.neliti.com/media/publications/39915-ID-stigmamasyarakat-terhadap orang -dengan-hivaids.pdf. Diakses tanggal 20-04-19.

Sarikusuma, dkk, 2012, Konsep Diri Orang Dengan HIV Dan AIDS (Odha) Yang Menerima Label Negative Dan Diskriminsi Dari Lingkungan Sosial, jurnal Psikologi onlain, Vol. 1. Http://www.researchgate.net/publication/316817736. Diakses tanggal 5-09-19.

Sudayo, et.al, 2009, Buku Ajar Penyakit Dalam. Jakarta: Internal publising;

Suhanda, I 2017, Stigma Sosial, Bagaimana Mengatasinya?, https://edukasi.kompas.com/read/2017 /09/08/06270121/stigma sosial bagaimana mengatasinya?page=all. 2017. Diakses pada tanggal 02-04-2019.

Sosilo, I, 2013, Buku pedoman penghapusan stigma dan diskriminasi bagi pengelola petugas layanan kesehatan dan kader, https://www.slideshare.net/irenesusilo18/juknis-hiv-pedomanstigma-diskriminasi, Diakses pada tanggal 07-07-2019.

Sujarweni, W, 2015, Statistik Untuk Kesehatan, Yogyakarta: Gava Media; 
Tatang, 2016, Supervisi Pendidikan, Bandung: Cv Pustaka Setia;

Tianingrum,Niken Agus, 2018, Pengaruh Keterpaparan Informasi Terhadap Stigma Hiv\&Aids Pada Pelajar Sma,Jurnal Ilmu Kesehatan, Vol. 6 No. 1, http://journals.umkt.ac.id, Diakses pada tanggal 5-09-19.

Wati, S, N, 2017, Kenali dan hentikan berbagai stigma yang melekat pada ODHA (orang dengan HIV/AIDS), https://hellosehat.com/hidupsehat/psikologi/diskriminasi-stigma-terhadap-odha/. Diakses pada tanggal 02-04-2019.

Wahyuni,s., Ronoadmodjo,s., 2016, Hubungan antara pengetahuan hiv/aids dengan sikap penolakan terhadap orang dengan hiv/aids (odha) pada masyarakat indonesia (analisis lanjut survei demografi dan kesehatan Indonesia 2012), Jurnal Kesehatan Reproduksi, https://media.neliti.com/media/publications/108231-ID-hubungan-antara-pengetahuanhivaids-deng.pdf, Diakses tanggal 20-04-19. 